\title{
RELATIONSHIP BETWEEN SYMPATHETIC NERVE ACTIVITY AND AORTIC WAVE REFLECTION CHARACTERISTICS IN POSTMENOPAUSAL WOMEN
}

\author{
Emma C. Hart, Ph.D. ${ }^{1}$, Nisha Charkoudian, Ph.D. ${ }^{2}$, Michael J. Joyner, M.D. ${ }^{1}$, Jill N. Barnes, \\ Ph.D. ${ }^{1}$, Timothy B. Curry, M.D., Ph.D. ${ }^{1}$, and Darren P. Casey, Ph.D. ${ }^{1}$ \\ ${ }^{1}$ Department of Anesthesiology, Mayo Clinic, Rochester, MN, USA \\ ${ }^{2}$ Thermal \& Mountain Medicine Division US Army Research Institute of Environmental Medicine, \\ Natick, MA, USA
}

\section{Abstract}

OBJECTIVE-Aortic wave reflection characteristics, such as augmentation index, are positively related to muscle sympathetic nerve activity in young men. In young women, there is an inverse relationship. We investigated whether this inverse relationship persisted in postmenopausal women.

\begin{abstract}
METHODS-Muscle sympathetic nerve activity (peroneal microneurography) and arterial pressure (brachial catheter) were measured in 16 postmenopausal women (age; mean \pm SEM, $60 \pm$ 2 yrs.). Aortic blood pressure and wave form characteristics were synthesized from radial arterial pressure waves (applanation tonometry). Specifically, augmentation index, wave reflection amplitude and estimated wasted left ventricular energy were calculated. These data were compared to our previously published work from an identical protocol in 23 young women $(25 \pm 1$ yrs.).
\end{abstract}

RESULTS-Tonic sympathetic activity was higher in postmenopausal vs. young women (64 \pm 3 vs. $24 \pm 4$ bursts/100 heart beats). All indices of aortic wave reflection were higher in the postmenopausal vs. young women $(P<0.05)$. Baseline sympathetic activity was inversely related to augmentation index $(\mathrm{r}=-0.63, P<0.05)$, augmented pressure $(\mathrm{r}=-0.62, P<0.05)$ and wasted left ventricular energy $(\mathrm{r}=-0.61, P<0.05)$ in young women. Conversely, baseline sympathetic activity was positively related to augmentation index $(\mathrm{r}=0.63 ; P=0.09)$, augmented pressure $(\mathrm{r}=0.69$, $P<0.05)$ and wasted left ventricular energy $(\mathrm{r}=0.79, P<0.05)$ in postmenopausal women.

CONCLUSIONS-High levels of sympathetic activity are associated with higher indices of aortic wave reflection in postmenopausal women. Consequently, postmenopausal women with high sympathetic activity may be more at risk of developing cardiovascular disease or adverse cardiovascular related events.

\section{Keywords}

aortic pressure; sympathetic nerve activity; menopause; women; pressure wave reflection

Corresponding Author: Darren P. Casey, Ph.D., Department of Anesthesiology, Mayo Clinic, 200 First St. SW, Rochester, MN 55905, Phone: (507) 255-2208, Fax: (507) 255-7300, casey.darren@ mayo.edu.

Conflicts of interest: None 


\section{Introduction}

In women, the risk of developing cardiovascular disease (e.g. hypertension) and experiencing cardiovascular related events (e.g. stroke) increases following menopause. ${ }^{1-3}$ This is associated with a gradual increase in arterial pressure as women age, which becomes more markedly elevated around the onset of menopause. ${ }^{1}$ The increase in arterial pressure in aging women, is associated with a concomitant increase in sympathetic nerve activity ${ }^{4,5}$ and stiffening of the large elastic arteries. ${ }^{6,7}$ Increased arterial stiffness causes an elevation in pulse wave velocity which can have a profound effect on central aortic pressures. In this context, 'stiffer' vessels promote early return of pressure waves which are reflected back to the heart from peripheral sites. Consequently, the pressure waves arrive early during systole instead of diastole. Early return of pressure waves causes an elevation in ascending aortic systolic and pulse pressure, which in turn causes an increase in afterload. In general, increased amplitude of the reflected pressure waves, to the heart, is associated with increased risk of experiencing adverse cardiovascular events. ${ }^{8-10}$ Along these lines, it is well documented that postmenopausal women have an elevation in arterial stiffness 6,7 and consequently increased indexes of aortic wave reflection. ${ }^{11,12}$

We recently reported that among young men, muscle sympathetic nerve activity (MSNA) is positively related to indexes of aortic wave reflection. ${ }^{13}$ Therefore, men with high MSNA had higher indexes of aortic wave reflection. However and interestingly, we found that among young women this relationship became negative. That is, young women with high MSNA had lower indexes of aortic wave reflection. This suggests that in young men, high levels of MSNA negatively affect aortic hemodynamics to a greater extent than in young women and identifies further mechanisms by which the female sex hormones modify cardiovascular risk factors and protect the cardiovascular system from the detrimental effects of high sympathetic nerve activity. Whether this apparent protective mechanism is abolished in postmenopausal women is unknown. Therefore, we hypothesized that in postmenopausal women, sympathetic nerve activity would have a negative effect on indexes of aortic wave reflection, similar to that observed in young men but not in young women. Thus, the aim of this study was to examine whether there was a relationship between MSNA and indexes of aortic wave reflection in postmenopausal women. We compared a group of postmenopausal women to data from the young women who participated in our previous study. ${ }^{13}$.

\section{Methods}

\section{Participants}

After the protocol was approved by the Institutional Review Board of the Mayo Clinic, 19 postmenopausal women gave written informed consent to participate in this study (Table 1 for demographics). However, we could not obtain sympathetic recordings in 3 of the postmenopausal women. Therefore, the data reported represents that from 16 postmenopausal women. In addition, data from our previous study in 23 young women ${ }^{13}$ were used for comparison with our present group of older women. The participants were non-smokers with no history of cardiovascular or other chronic diseases and were recreationally active. One postmenopausal woman had a history of smoking, but ceased 4 years prior to the experiment. Participants were excluded if their body mass index was $\geq 28$ $\mathrm{kg} / \mathrm{m}^{2}$ or if they were taking any anti-hypertensive medications. Young women taking oral contraceptives were included in this study. Postmenopause was defined as at least one year since last menstruation. ${ }^{14}$ Postmenopausal women on hormone therapy were excluded from this study. All women of child bearing age were asked to complete a pregnancy test at least 48 hours before the study day. Young women were tested in the low hormone phase of their cycle (during the placebo phase for oral contraceptives and luteal phase for normally 
menstruating women). Participants fasted overnight and were asked not to consume caffeine or alcohol for 24 hours before the experiment. All study protocols were performed according to the Declaration of Helsinki.

\section{Measurements}

All studies were performed in a Center for Translational Science Activities (CTSA) based Clinical Research Unit laboratory at the Mayo Clinic, where ambient temperature was controlled between $22^{\circ} \mathrm{C}$ and $24^{\circ} \mathrm{C}$. On arrival to the laboratory, participants rested in the supine position during instrumentation. A 20 gauge, $5 \mathrm{~cm}$ catheter was placed in the brachial artery of the left arm under aseptic conditions after local anesthesia ( $2 \%$ lidocaine). The catheter was connected to a pressure transducer, which was positioned at the level of the heart and interfaced with a personal computer to monitor arterial pressure. A 3-lead ECG was used for continuous recording of heart rate.

MSNA was recorded with a tungsten microelectrode in the peroneal nerve, posterior to the fibular head, as described by Sundlöf and Wallin ${ }^{15}$. The recorded signal was amplified 80,000-fold, band-pass filtered (700 to $2000 \mathrm{~Hz}$ ), rectified and integrated (resistancecapacitance integrator circuit, time constant $0.1 \mathrm{~s}$ ) by a nerve-traffic analyzer.

The assessment of arterial wave reflection characteristics was performed non-invasively using the SphygmoCor system (AtCor Medical, Sydney, Australia) described previously. ${ }^{16}$ Briefly, high-fidelity radial artery pressure waveforms were recorded by applanation tonometry of the radial pulse in the right wrist using a "pencil type" micromanometer (Millar Instruments, Houston, Texas). The radial BP and waveforms were calibrated from the systolic and diastolic brachial artery BP (catheter). A validated, generalized transfer function was used to generate the corresponding aortic pressure waveform. ${ }^{17}$ The generalized transfer function has been validated using both intra-arterially ${ }^{17-19}$ and noninvasively ${ }^{20}$ obtained radial pressure waves in a range of participants including coronary bypass patients (aged 49-78). ${ }^{21}$

Pulse wave analysis of the aortic pressure waveform provided the following key variables of interest: aortic pressures, aortic augmentation index $\left(\mathrm{AI}_{\mathrm{x}}\right), \mathrm{AI}_{\mathrm{X}}$ adjusted for a $\mathrm{HR}$ of 75 beats/min $\left(\mathrm{AI}_{\mathrm{x}} @ 75\right.$ beats $\left./ \mathrm{min}\right)$ and wasted left ventricular $(\mathrm{LV})$ pressure energy $\left(\mathrm{E}_{\mathrm{w}}\right)$, which is the component of extra myocardial oxygen requirement due to early systolic wave reflection. ${ }^{13,16,22}$ Augmentation index is adjusted for heart rate because of the inverse linear relationship between the two variables. ${ }^{23} \mathrm{E}_{\mathrm{w}}$ can be estimated as $[(\pi / 4) *($ augmented pressure $\left.\times \Delta \mathrm{t}_{\mathrm{r}}\right) * 1.333$ ], where 1.333 is the conversion factor for $\mathrm{mmHg} / \mathrm{s}$ to dynes $\cdot \mathrm{cm}^{-2} \cdot \mathrm{s}$ and $\Delta \mathrm{t}_{\mathrm{r}}$ is the systolic duration of the reflected wave. Augmented pressure (AP) is defined as the difference between the first (forward wave) and second systolic shoulders of the aortic systolic blood pressure and is a result of the merging of forward and reflected pressure waves. Only high-quality recordings, defined as an in-device quality index of over $80 \%$ (derived from an algorithm including average pulse height variation, diastolic variation, and the maximum rate of rise of the peripheral waveform), were accepted for analysis.

\section{Protocol}

After placement of the arterial catheter, participants were asked to rest supine during instrumentation of microneurography. Once a satisfactory site for measurement of MSNA was located, 15 minutes of baseline data were recorded with the subject resting quietly. Subsequently, duplicate applanation tonometry measurements were made.

Arterial line placement was unsuccessful in 2 of the young women. Therefore, data regarding stroke volume, cardiac output and TPR are calculated in 21 of the 23 young women. In these participants, an average of 3 automated brachial blood pressure readings 
were used to calibrate radial pressure waveforms during the applanation tonometry measurements.

\section{Data Analysis}

Data were collected at $240 \mathrm{~Hz}$, stored on a computer and analyzed off-line with signal processing software (WinDaq, DATAQ Instruments, Akron, $\mathrm{OH}$ ). Blood pressures (systolic and diastolic blood pressures; SBP, DBP) were calculated from the arterial wave form measured from the brachial artery. Mean arterial pressure (MAP) was calculated as the time integral over the pulse pressure (PP). Beat-to-beat stroke volume was calculated from the brachial arterial pulse pressure wave by model flow analysis. Model flow computes an aortic waveform based on nonlinear pressure-volume, pressure-compliance and pressurecharacteristic impedance equations, incorporating age, sex, height and body mass. ${ }^{24}$ Cardiac output was calculated as the average stroke volume measured over 5 minutes multiplied by the heart rate measured over the same 5 minute rest period. Stroke volume and cardiac output under normothermic resting conditions measured using Modelflow analysis compares well to that estimated by thermodilution ${ }^{25,26}$ and Doppler ultrasound ${ }^{27}$. Total peripheral resistance (TPR) was calculated as MAP/cardiac output. MAP, heart rate, stroke volume, cardiac output, TPR and MSNA were averaged from the last 5 minutes of the 15 minute rest period.

Sympathetic bursts in the integrated neurogram were identified by a custom-manufactured semi-automated analysis program ${ }^{28,} 29$ burst identification was controlled visually by a single investigator $(\mathrm{ECH})$. The program then compensated for baroreflex latency, and associated each sympathetic burst with the appropriate cardiac cycle. All pulse wave analysis variables are reported as the mean of 2 applanation tonometry measurements for each individual.

\section{Statistical Analyses}

Group data are expressed as means \pm SEMs. Differences in MSNA, hemodynamic variables, and aortic wave reflection characteristics in young and older women were evaluated using a 2 -tailed independent $t$ test. To access the relationships between MSNA and aortic wave reflection characteristics, linear regression analysis was performed and Pearson's correlation coefficients calculated. The critical a-level was set at 0.05 , and data were analyzed using SigmaStat software (version 2.03, SPSS Inc.).

\section{Results}

\section{Average group neural-hemodynamic and aortic wave reflection variables}

Subject demographics are presented in Table 1. There were no differences in height, body mass and body surface area between the young and older women.

Table 2 outlines average group differences in neural, hemodynamic and aortic wave reflection characteristics. Stroke volume and cardiac output were lower in the postmenopausal women compared to the young women $(P<0.05)$. Total peripheral resistance and brachial and aortic pressures (apart from DBP) were greater in the postmenopausal women vs. the young women $(P<0.05)$. In addition, indexes of aortic wave reflection were higher in the postmenopausal women compared to their younger counterparts $(P<0.05)$. Therefore, the estimated $\mathrm{E}_{\mathrm{w}}$ was greater in the postmenopausal women vs. the young women $(P<0.05)$. As expected, MSNA (burst incidence and burst frequency) were also greater in the postmenopausal group compared to the young women. 


\section{Relationships between neural-hemodynamic variables and aortic wave reflection characteristics}

Previously we reported that there was no relationship of MSNA to aortic pressures (Table 3) or TPR $(r=0.14)$ in the young women. ${ }^{13}$ Interestingly, in older women, MSNA was positively related to TPR $(\mathrm{r}=0.56, P=0.02)$ and aortic SBP and PP (Figure 1; Table 3, $P=$ $0.01)$. In the young women, we found that MSNA was inversely related to $\mathrm{AI}_{\mathrm{x}}, \mathrm{AP}$ and $\mathrm{E}_{\mathrm{W}}$ $(P<0.05)$. In complete contrast to the young women, MSNA was positively related to $\mathrm{AI}_{\mathrm{x}}$ ( $P=0.01$; Figure 2$), \mathrm{AI}_{\mathrm{x}}$ at 75 beats/min $(P=0.02), \mathrm{AP}$ and $\mathrm{E}_{\mathrm{W}}(P=0.001)$ in the older women.

\section{Discussion}

The major new finding of the present study is that the level of resting MSNA is positively related to aortic systolic and pulse pressures and indexes of aortic wave reflection in postmenopausal women. Therefore, postmenopausal women with higher MSNA, have higher aortic pressures and indexes of aortic wave reflection. These relationships are in contrast to those observed in young women, where MSNA is not related to aortic pressures and inversely related to measures of aortic wave reflection. ${ }^{13}$

\section{Aortic wave reflection, aortic pressures and MSNA}

In postmenopausal women we (and others) have shown that indexes of aortic wave reflection (even when normalized for heart rate), aortic blood pressures (systolic and pulse pressure), peripheral blood pressures (systolic and pulse pressures) and MSNA were elevated compared to young women. 6,11 These factors are independent predictors for the development of cardiovascular disease, incidence of cardiovascular related events and allcause mortality. ${ }^{10,30}$ This is in part due to the fact that early return of the reflected waves leads to an increase in aortic pressure and thus an increase in afterload.

Recently, studies have indicated that MSNA may be linked to the amplitude of the reflected pressure waves and the level of aortic arterial stiffness in humans. ${ }^{13,31}$ Data from our laboratory demonstrated that MSNA was related to indexes of aortic wave reflection among individuals. Furthermore, these findings indicated that the observed relationships were dependent on sex. In this context, MSNA was positively related to aortic wave reflection characteristics in young men, but inversely related in young women. Thus, young women with higher MSNA showed a lower augmentation index, whilst young men with high MSNA had a high augmentation index.

In the present study, we demonstrate that in older women, the relationship between MSNA and aortic wave reflection characteristics is reversed compared to young women, and becomes positive so it is similar to that in young men. MSNA was positively related to augmented pressure and augmentation index in the postmenopausal women (Figure 2). This relationship persisted when augmentation index was normalized for heart rate (Table 3). Augmentation index is directly affected by heart rate, that is; augmentation index is inversely related to heart rate, so that higher heart rates caused a lower augmentation index..$^{23}$ Therefore heart rate was not driving the relationship between MSNA and augmentation in postmenopausal women. These data suggest that, postmenopausal women with high MSNA had higher amplitude of the reflected pressure wave, and vice versa in postmenopausal women with low MSNA. The elevated amplitude of the reflected pressure wave which arrives at the LV during systole causes an increase in afterload. Consequently, women with high MSNA also had a high estimate of $\mathrm{E}_{\mathrm{w}}$; an index of myocardial oxygen demand and left ventricular work. $E_{w}$ is the portion of the tension-time index curve attributed to earlier reflection of the pulse pressure wave which increases central aortic 
pressure during systole. An increase in $\mathrm{E}_{\mathrm{w}}$ can be interpreted as an excess amount of energy expended by the LV without a proportionate increase in flow ${ }^{16}$ and is associated with left ventricular hypertrophy ${ }^{22}$. Therefore, it is possible that high levels of MSNA in postmenopausal women can indirectly increase myocardial work and the demand placed on the LV by increasing the amplitude of the reflected pressure waves from the periphery; leading to amplified aortic pressures.

Interestingly, in the present study, there was a relationship between MSNA and aortic systolic and pulse pressure in postmenopausal women (Figure 1), which did not exist in young women or men. ${ }^{13}$ Consequently postmenopausal women with high MSNA had high aortic systolic and pulse pressures. This suggests that as women age, MSNA may become more important in determining central aortic pressure. This may have important consequences since elevated aortic pulse pressure is more strongly related to vascular disease and cardiovascular events than brachial blood pressures. ${ }^{32}$

\section{Why are the relationships opposite in young and older women?}

The inverse relationship between MSNA and indexes of aortic wave reflection in young women becomes positive in postmenopausal women so it becomes similar to that in young men. This suggests a role for the female sex hormones in modifying this relationship. Along these lines recent data demonstrate a possible role for the female sex hormones in modifying the transduction of MSNA into peripheral vascular tone. ${ }^{33}$ Exactly how the sex hormones might modulate the effect of MSNA on the vasculature is unclear. Data from our laboratory and others suggest that differences in $\beta$-adrenergic sensitivity to norepinephrine play a role. ${ }^{34,35}$ For example, vasoconstriction in response to norepinephrine infusion in the forearm is enhanced following $\beta$-blockade in young women, but not in young men ${ }^{34,35}$ or postmenopausal women ${ }^{34}$. Thus, in young women, vasoconstrictor tone caused by norepinephrine release from the sympathetic nerve endings is offset by concurrent $\beta$ adrenergic receptor stimulation. Consequently, high levels of MSNA in young women may decrease aortic waveform characteristics via decreased vascular tone or stiffness via vascular $\beta$-adrenergic receptor stimulation. This appears to become reversed as women age and become postmenopausal. Data from our laboratory suggests that as women age this $\beta$ adrenergic vasodilator effect decreases and is minimal in post-menopausal women. ${ }^{34}$

It should be noted that changes in the cardiovascular system that occur as part of a normal aging process might also have an impact on the interactions observed between indexes of aortic wave reflection and MSNA. Aging is also associated with endothelial dysfunction, ${ }^{36,37}$ desensitization of a-adrenergic receptors, ${ }^{34,} 38,39$ increased reactive oxygen species ${ }^{40}$ and decreased blood volume relative to fat free mass ${ }^{41,42}$. Consequently, because we did not directly test whether the female sex hormones are involved in modifying the relationships described above in older postmenopausal women, we cannot rule out the possibility that normal healthy aging also plays a crucial role.

\section{Limitations}

Age associated increases in aortic stiffness likely contributed to the elevated baseline wave reflection characteristics we observed in the postmenopausal women (Table 2). ${ }^{6,11}$ Unfortunately, we did not directly measure regional arterial stiffness (i.e. PWV) in the current study (similar to our first paper; ${ }^{13}$ ). Therefore, we are unable to determine if the relationship between MSNA and wave reflection characteristics in postmenopausal women were related to aortic PWV. Along these lines, future studies are warranted to elucidate whether the change in the relationship between MSNA and aortic wave reflection that occurs in aging women is driven by aortic stiffness. 
In addition, the group of postmenopausal women may be viewed as a relatively low sample size $(n=16)$. Since we included a smaller sample size we could not complete multiple regression analysis on our data as smaller sample sizes increase the chance that we will inflate the multiple regression correlation coefficients. In this case we may find relationships where there are none. However, the sample size included in this investigation is not different to many other studies with high impact findings involving groups of healthy postmenopausal women. ${ }^{35,43}$ This is related to the fact that it is difficult to recruit healthy postmenopausal women that are not taking anti-hypertensive medications and/or hormone therapy.

Finally, concerns regarding our comparison of young women to older postmenopausal women have been raised. Since we compare young women to a much older population, it is hard to draw conclusions regarding whether differences in these populations are due to alterations in circulating levels of sex hormones or age per se. However, we also compare our data to that found in young men. In our previous publication we showed that young men with high MSNA have a high augmentation index. ${ }^{13}$ This was the opposite in young women, where MSNA was in fact inversely related to augmentation index. Because we can compare our group of postmenopausal women to a group of young men (as well as young women), we can hypothesize that the change we see in older women, is not purely due to the aging process. Consequently, this supports the assertion that the female sex hormones do in fact offset the effect on augmentation index and thus the afterload that the left ventricle has to contend with. This adds further evidence that in older postmenopausal women, it is important to prevent increases in sympathetic nerve activity.

\section{Perspectives}

Young women appear to be protected against the possible detrimental effects of high sympathetic nerve activity on the cardiovascular system. ${ }^{13}$ Interestingly, this protective effect disappears in older postmenopausal women. In older women; there is an increase in MSNA which may be due to an interaction between aging and the onset of menopause in women. Moreover, there is an alteration in the way the MSNA interacts with vasculature in postmenopausal women. Here we show evidence that postmenopausal women with high sympathetic nerve activity not only have higher levels of peripheral blood pressures, but also have higher levels of aortic blood pressure and aortic wave reflection (the latter is also a relationship which is observed in young men and not in young women). Together, these variables may increase LV workload and thus myocardial oxygen demand. The positive relationship between MSNA and aortic blood pressures, combined with a general increase in MSNA may explain why older postmenopausal women have an increased risk of developing cardiovascular diseases and cardiac related events (such as myocardial infarction).

Furthermore, these data raise the possibility that when women with high levels of MSNA become menopausal, they are more likely to develop LV hypertrophy and become more at risk of experiencing CV related events. ${ }^{10,} 44$

\section{Conclusions}

In summary, we found that the inverse relationship between MSNA and indexes of aortic wave reflection we previously observed in young women is positive in postmenopausal women, so it is similar to that in young men. Thus, postmenopausal women with high MSNA have higher indexes of aortic wave reflection and estimated LV work. The present data are therefore consistent with our and others' previous reports showing that the female sex hormones modulate the effects of MSNA on the vasculature. ${ }^{34,45}$ Finally, the mechanisms we present in the present report likely contribute to the increased risk of cardiovascular disease and specific cardiovascular events in older women. This highlights the need to prevent rises in sympathetic activity in postmenopausal women. However, the best method to achieve this aim remains ambiguous. 


\section{Acknowledgments}

Thank you to Shelly Roberts, Jean Knutson, Karen Krucker, Jessica Sawyer and Christopher Johnson for their nursing and technical support. We also thank research recruiters; Pamela Engrav and Nancy Meyer. Finally we are grateful to the women for participating in this study.

Sources of funding: This study was supported by NIH HL083947 (MJJ, BGW, NC), AR55819 (DPC), AG038067 (JNB) and AHA 070036Z (ECH). This projected was also supported by grant 1 UL1 RR024150 from the National Center for Research Resources (NCRR) and its contents are solely the responsibility of the authors and do not necessarily represent the official view of NCRR or NIH. Additional support came from the Mayo Foundation including a philanthropic gift from the Caywood family and the Mayo Clinic Department of Anesthesia.

\section{References}

1. Burt VL, Whelton P, Roccella EJ, Brown C, Cutler JA, Higgins M, Horan MJ, Labarthe D. Prevalence of hypertension in the us adult population. Results from the third national health and nutrition examination survey, 1988-1991. Hypertension. 1995; 25:305-313. [PubMed: 7875754]

2. Lloyd-Jones DM, Evans JC, Levy D. Hypertension in adults across the age spectrum: Current outcomes and control in the community. Jama. 2005; 294:466-472. [PubMed: 16046653]

3. Wiinberg N, Hoegholm A, Christensen HR, Bang LE, Mikkelsen KL, Nielsen PE, Svendsen TL, Kampmann JP, Madsen NH, Bentzon MW. 24-h ambulatory blood pressure in 352 normal danish subjects, related to age and gender. Am J Hypertens. 1995; 8:978-986. [PubMed: 8845079]

4. Matsukawa T, Sugiyama Y, Watanabe T, Kobayashi F, Mano T. Gender difference in age-related changes in muscle sympathetic nerve activity in healthy subjects. Am J Physiol. 1998; 275:R16001604. [PubMed: 9791079]

5. Narkiewicz K, Phillips BG, Kato M, Hering D, Bieniaszewski L, Somers VK. Gender-selective interaction between aging, blood pressure, and sympathetic nerve activity. Hypertension. 2005; 45:522-525. [PubMed: 15767469]

6. Tanaka H, Dinenno FA, Hunt BE, Jones PP, DeSouza CA, Seals DR. Hemodynamic sequelae of age-related increases in arterial stiffness in healthy women. Am J Cardiol. 1998; 82:1152-1155. A1110. [PubMed: 9817505]

7. Vaitkevicius PV, Fleg JL, Engel JH, O’Connor FC, Wright JG, Lakatta LE, Yin FC, Lakatta EG. Effects of age and aerobic capacity on arterial stiffness in healthy adults. Circulation. 1993; 88:1456-1462. [PubMed: 8403292]

8. Manisty C, Mayet J, Tapp RJ, Parker KH, Sever P, Poulter NR, Thom SA, Hughes AD. Wave reflection predicts cardiovascular events in hypertensive individuals independent of blood pressure and other cardiovascular risk factors: An ascot (anglo-scandinavian cardiac outcome trial) substudy. J Am Coll Cardiol. 2010; 56:24-30. [PubMed: 20620713]

9. Vlachopoulos C, Aznaouridis K, O’Rourke MF, Safar ME, Baou K, Stefanadis C. Prediction of cardiovascular events and all-cause mortality with central haemodynamics: A systematic review and meta-analysis. Eur Heart J. 2010; 31:1865-1871. [PubMed: 20197424]

10. Weber T, Auer J, O’Rourke MF, Kvas E, Lassnig E, Berent R, Eber B. Arterial stiffness, wave reflections, and the risk of coronary artery disease. Circulation. 2004; 109:184-189. [PubMed: 14662706]

11. Casey DP, Pierce GL, Howe KS, Mering MC, Braith RW. Effect of resistance training on arterial wave reflection and brachial artery reactivity in normotensive postmenopausal women. Eur J Appl Physiol. 2007; 100:403-408. [PubMed: 17394009]

12. McEniery CM, Yasmin, Hall IR, Qasem A, Wilkinson IB, Cockcroft JR. Normal vascular aging: Differential effects on wave reflection and aortic pulse wave velocity: The anglo-cardiff collaborative trial (acct). J Am Coll Cardiol. 2005; 46:1753-1760. [PubMed: 16256881]

13. Casey DP, Curry TB, Joyner MJ, Charkoudian N, Hart EC. Relationship between muscle sympathetic nerve activity and aortic wave reflection characteristics in young men and women. Hypertension. 2011; 57:421-427. [PubMed: 21242459]

14. Gracia CR, Sammel MD, Freeman EW, Lin H, Langan E, Kapoor S, Nelson DB. Defining menopause status: Creation of a new definition to identify the early changes of the menopausal transition. Menopause. 2005; 12:128-135. [PubMed: 15772558] 
15. Sundlof G, Wallin BG. The variability of muscle nerve sympathetic activity in resting recumbent man. J Physiol. 1977; 272:383-397. [PubMed: 592196]

16. Nichols WW, Singh BM. Augmentation index as a measure of peripheral vascular disease state. Curr Opin Cardiol. 2002; 17:543-551. [PubMed: 12357133]

17. Pauca AL, O'Rourke MF, Kon ND. Prospective evaluation of a method for estimating ascending aortic pressure from the radial artery pressure waveform. Hypertension. 2001; 38:932-937. [PubMed: 11641312]

18. Chen CH, Nevo E, Fetics B, Pak PH, Yin FC, Maughan WL, Kass DA. Estimation of central aortic pressure waveform by mathematical transformation of radial tonometry pressure. Validation of generalized transfer function. Circulation. 1997; 95:1827-1836. [PubMed: 9107170]

19. Weber T, Wassertheurer S, Rammer M, Maurer E, Hametner B, Mayer CC, Kropf J, Eber B. Validation of a brachial cuff-based method for estimating central systolic blood pressure. Hypertension. 2011; 58:825-832. [PubMed: 21911710]

20. Gallagher D, Adji A, O'Rourke MF. Validation of the transfer function technique for generating central from peripheral upper limb pressure waveform. Am J Hypertens. 2004; 17:1059-1067. [PubMed: 15533735]

21. Bogert LW, Wesseling KH, Schraa O, Van Lieshout EJ, de Mol BA, van Goudoever J, Westerhof $\mathrm{BE}$, van Lieshout JJ. Pulse contour cardiac output derived from non-invasive arterial pressure in cardiovascular disease. Anaesthesia. 2010; 65:1119-1125. [PubMed: 20860647]

22. Hashimoto J, Nichols WW, O'Rourke MF, Imai Y. Association between wasted pressure effort and left ventricular hypertrophy in hypertension: Influence of arterial wave reflection. Am J Hypertens. 2008; 21:329-333. [PubMed: 18202668]

23. Wilkinson IB, MacCallum H, Flint L, Cockcroft JR, Newby DE, Webb DJ. The influence of heart rate on augmentation index and central arterial pressure in humans. J Physiol. 2000; 525(Pt 1): 263-270. [PubMed: 10811742]

24. Wesseling KH, Jansen JR, Settels JJ, Schreuder JJ. Computation of aortic flow from pressure in humans using a nonlinear, three-element model. J Appl Physiol. 1993; 74:2566-2573. [PubMed: 8335593]

25. Harms MP, Wesseling KH, Pott F, Jenstrup M, Van Goudoever J, Secher NH, Van Lieshout JJ. Continuous stroke volume monitoring by modelling flow from non-invasive measurement of arterial pressure in humans under orthostatic stress. Clin Sci (Lond). 1999; 97:291-301. [PubMed: 10464054]

26. Shibasaki M, Wilson TE, Bundgaard-Nielsen M, Seifert T, Secher NH, Crandall CG. Modelflow underestimates cardiac output in heat-stressed individuals. Am J Physiol Regul Integr Comp Physiol. 2011; 300:R486-491. [PubMed: 21084673]

27. van Lieshout JJ, Toska K, van Lieshout EJ, Eriksen M, Walloe L, Wesseling KH. Beat-to-beat noninvasive stroke volume from arterial pressure and doppler ultrasound. Eur J Appl Physiol. 2003; 90:131-137. [PubMed: 12851826]

28. Charkoudian N, Joyner MJ, Johnson CP, Eisenach JH, Dietz NM, Wallin BG. Balance between cardiac output and sympathetic nerve activity in resting humans: Role in arterial pressure regulation. J Physiol. 2005; 568:315-321. [PubMed: 16037092]

29. Kienbaum P, Karlssonn T, Sverrisdottir YB, Elam M, Wallin BG. Two sites for modulation of human sympathetic activity by arterial baroreceptors? J Physiol. 2001; 531:861-869. [PubMed: 11251065]

30. Franklin SS, Gustin Wt, Wong ND, Larson MG, Weber MA, Kannel WB, Levy D. Hemodynamic patterns of age-related changes in blood pressure. The framingham heart study. Circulation. 1997; 96:308-315. [PubMed: 9236450]

31. Swierblewska E, Hering D, Kara T, Kunicka K, Kruszewski P, Bieniaszewski L, Boutouyrie P, Somers VK, Narkiewicz K. An independent relationship between muscle sympathetic nerve activity and pulse wave velocity in normal humans. J Hypertens. 2010; 28:979-984. [PubMed: 20408258]

32. Roman MJ, Devereux RB, Kizer JR, Lee ET, Galloway JM, Ali T, Umans JG, Howard BV. Central pressure more strongly relates to vascular disease and outcome than does brachial pressure: The strong heart study. Hypertension. 2007; 50:197-203. [PubMed: 17485598] 
33. Hart EC, Charkoudian N, Wallin BG, Curry TB, Eisenach JH, Joyner MJ. Sex differences in sympathetic neural-hemodynamic balance: Implications for human blood pressure regulation. Hypertension. 2009; 53:571-576. [PubMed: 19171792]

34. Hart EC, Charkoudian N, Wallin BG, Curry TB, Eisenach J, Joyner MJ. Sex and ageing differences in resting arterial pressure regulation: The role of the beta-adrenergic receptors. $\mathbf{J}$ Physiol. 2011; 589:5285-5297. [PubMed: 21859824]

35. Kneale BJ, Chowienczyk PJ, Brett SE, Coltart DJ, Ritter JM. Gender differences in sensitivity to adrenergic agonists of forearm resistance vasculature. J Am Coll Cardiol. 2000; 36:1233-1238. [PubMed: 11028476]

36. Donato AJ, Gano LB, Eskurza I, Silver AE, Gates PE, Jablonski K, Seals DR. Vascular endothelial dysfunction with aging: Endothelin-1 and endothelial nitric oxide synthase. Am J Physiol Heart Circ Physiol. 2009; 297:H425-432. [PubMed: 19465546]

37. Newcomer SC, Leuenberger UA, Hogeman CS, Proctor DN. Heterogeneous vasodilator responses of human limbs: Influence of age and habitual endurance training. Am J Physiol Heart Circ Physiol. 2005; 289:H308-315. [PubMed: 15778285]

38. Dinenno FA, Dietz NM, Joyner MJ. Aging and forearm postjunctional alpha-adrenergic vasoconstriction in healthy men. Circulation. 2002; 106:1349-1354. [PubMed: 12221051]

39. Smith EG, Voyles WF, Kirby BS, Markwald RR, Dinenno FA. Ageing and leg postjunctional alpha-adrenergic vasoconstrictor responsiveness in healthy men. J Physiol. 2007; 582:63-71. [PubMed: 17463044]

40. Bailey DM, McEneny J, Mathieu-Costello O, Henry RR, James PE, McCord JM, Pietri S, Young IS, Richardson RS. Sedentary aging increases resting and exercise-induced intramuscular free radical formation. J Appl Physiol. 2010; 109:449-456. [PubMed: 20507973]

41. Davy KP, Seals DR. Total blood volume in healthy young and older men. J Appl Physiol. 1994; 76:2059-2062. [PubMed: 8063668]

42. Jones PP, Davy KP, DeSouza CA, van Pelt RE, Seals DR. Absence of age-related decline in total blood volume in physically active females. Am J Physiol. 1997; 272:H2534-2540. [PubMed: 9227528]

43. Low DA, Hubing KA, Del Coso J, Crandall CG. Mechanisms of cutaneous vasodilation during the postmenopausal hot flash. Menopause. 2011; 18:359-365. [PubMed: 21107299]

44. Weber T, Auer J, Eber B, O'Rourke MF. Relationship between reduced elasticity of extracardiac vessels and left main stem coronary artery disease. Eur Heart J. 2004; 25:1966-1967. [PubMed: 15522475]

45. Hogarth AJ, Mackintosh AF, Mary DA. Gender-related differences in the sympathetic vasoconstrictor drive of normal subjects. Clin Sci (Lond). 2007; 112:353-361. [PubMed: 17129210] 

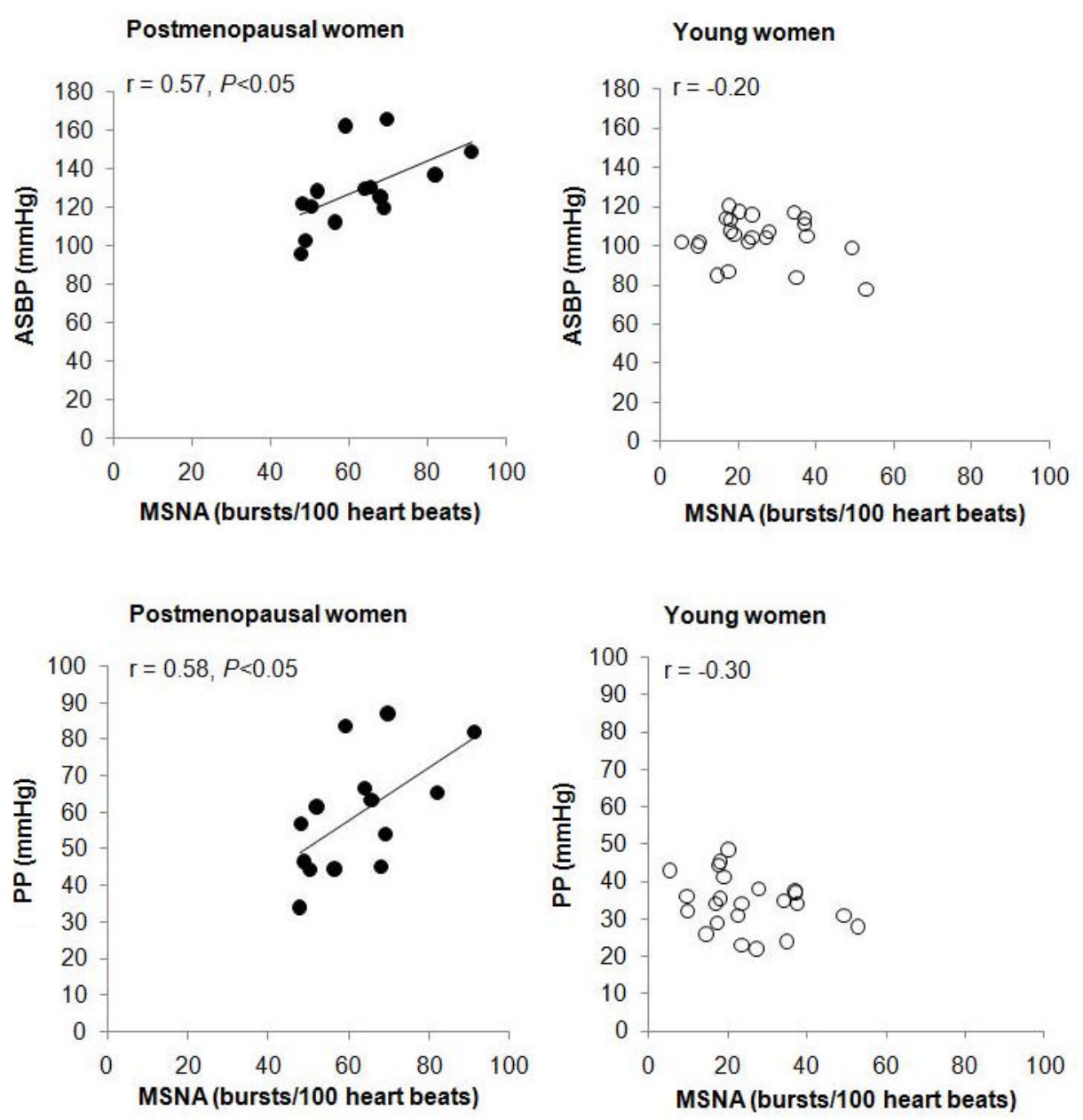

Figure 1.

Linear regression analysis of the relationship between MSNA (burst incidence) and aortic systolic blood pressure (ASBP, upper panel) and aortic pulse pressure (APP, lower panel) in postmenopausal $(n=16)$. We compared this to data collected in 23 young women in our laboratory that has been previously published (12). In the older women, the relationship of MSNA to ASBP and APP were positive so that postmenopausal women with high MSNA have a high ASBP and APP. Conversely, there was no such relationship in young women. See Table 3 for correlation coefficients. 

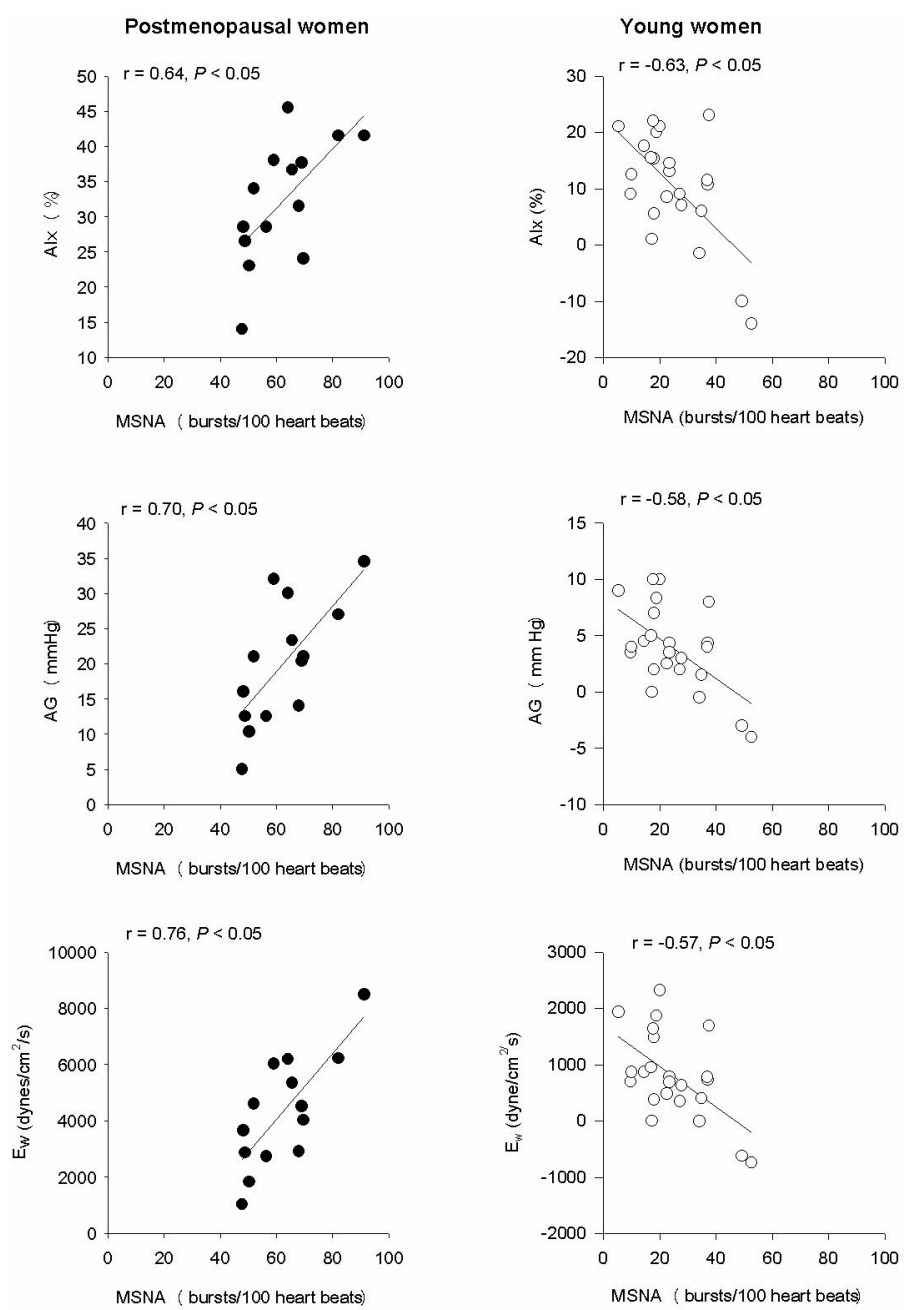

Figure 2.

Linear regression analysis of the relationship between MSNA (burst incidence) and augmentation index ( $\mathrm{AI}_{\mathrm{X}}$; bottom panel), augmented pressure (AP; middle panel) and wasted energy $\left(\mathrm{E}_{\mathrm{W}}\right.$; top panel) in postmenopausal $(\mathrm{n}=16)$. We compared this to data collected in 23 young women in our laboratory that has been previously published (12). In the older women, the relationship between MSNA and indexes of aortic wave reflection become positive so that postmenopausal women with high MSNA have higher indexes of aortic wave reflection, whereas, these relationships are inversely related in young women. See correlation coefficients in Table 3. 
Table 1

Participant demographics

\begin{tabular}{|l|l|l|}
\hline & Young women $(\mathbf{n}=\mathbf{2 3})$ & Older women $(\mathbf{n}=\mathbf{1 6})$ \\
\hline Age $(\mathbf{y r s})$ & $25 \pm 1$ & $60 \pm 2^{*}$ \\
\hline Body mass $(\mathbf{k g})$ & $64 \pm 2$ & $67 \pm 2$ \\
\hline Height $(\mathbf{c m})$ & $166 \pm 1$ & $165 \pm 2$ \\
\hline BMI $\left(\mathbf{k g} / \mathbf{m}^{\mathbf{2}}\right)$ & $24.2 \pm 0.5$ & $24.3 \pm 0.6$ \\
\hline
\end{tabular}

BMI; body mass index. Mean \pm SEM,

$P<0.05$ vs. young women 


\section{Table 2}

Neural-hemodynamic variables and aortic wave reflection characteristics in 23 young women and 16 postmenopausal women.

\begin{tabular}{|l|c|c|}
\hline Neural/hemodynamic variables & Young women & Older women \\
\hline Heart rate (beats/min) & $64 \pm 2$ & $59 \pm 2$ \\
\hline Stroke volume (ml) & $79 \pm 3$ & $67 \pm 2^{*}$ \\
\hline Cardiac output (1/min) & $5.0 \pm 0.2$ & $4.1 \pm 0.1^{*}$ \\
\hline TPR (mmHg///min) & $18.6 \pm 0.7$ & $24.8 \pm 1.1^{*}$ \\
\hline BSBP (mmHg) & $127 \pm 2$ & $145 \pm 5^{*}$ \\
\hline BDBP (mmHg) & $71 \pm 2$ & $72 \pm 2$ \\
\hline BMAP (mmHg) & $92 \pm 2$ & $99 \pm 3^{*}$ \\
\hline ASBP (mmHg) & $104 \pm 2$ & $131 \pm 5^{*}$ \\
\hline ADBP (mmHg) & $70 \pm 2$ & $72 \pm 2$ \\
\hline APP (mmHg) & $34 \pm 2$ & $63 \pm 4^{*}$ \\
\hline PPA & $1.65 \pm 0.06$ & $1.19 \pm 0.03^{*}$ \\
\hline AI $\mathbf{x}(\%)$ & $10 \pm 2$ & $33.4 \pm 2.2^{*}$ \\
\hline AI $\mathbf{x}_{\mathbf{x}}$ at 75 beats/min (\%) & $5 \pm 2$ & $25.8 \pm 2.1^{*}$ \\
\hline AP (mmHg) & $4 \pm 1$ & $22 \pm 3^{*}$ \\
\hline E (dynes/cm $/ \mathbf{s})$ & $788 \pm 161$ & $4861 \pm 605^{*}$ \\
\hline Ejection duration (ms) & $342 \pm 3$ & $355 \pm 4^{*}$ \\
\hline MSNA (bursts/100 heart beats) & $25 \pm 3$ & $64 \pm 3^{*}$ \\
\hline MSNA (bursts/min) & $16 \pm 2$ & $40 \pm 2^{*}$ \\
\hline
\end{tabular}

TPR; total peripheral resistance, BSBP; brachial systolic blood pressure, BDBP; brachial diastolic blood pressure, BMAP; brachial mean arterial pressure, ASBP; aortic SBP, ADBP; aortic DBP, APP; aortic pulse pressure, PPA; pulse pressure amplification, AIx; augmentation index, AP; augmented pressure, EW; wasted LV energy, MSNA; muscle sympathetic nerve activity. Mean \pm SEM,

${ }^{*} P<0.05$ vs. young women. NB: Stroke volume and thus TPR and cardiac output could not be calculated in 2 young women. Mean \pm SEM are calculated from 21 young women for these variables. 


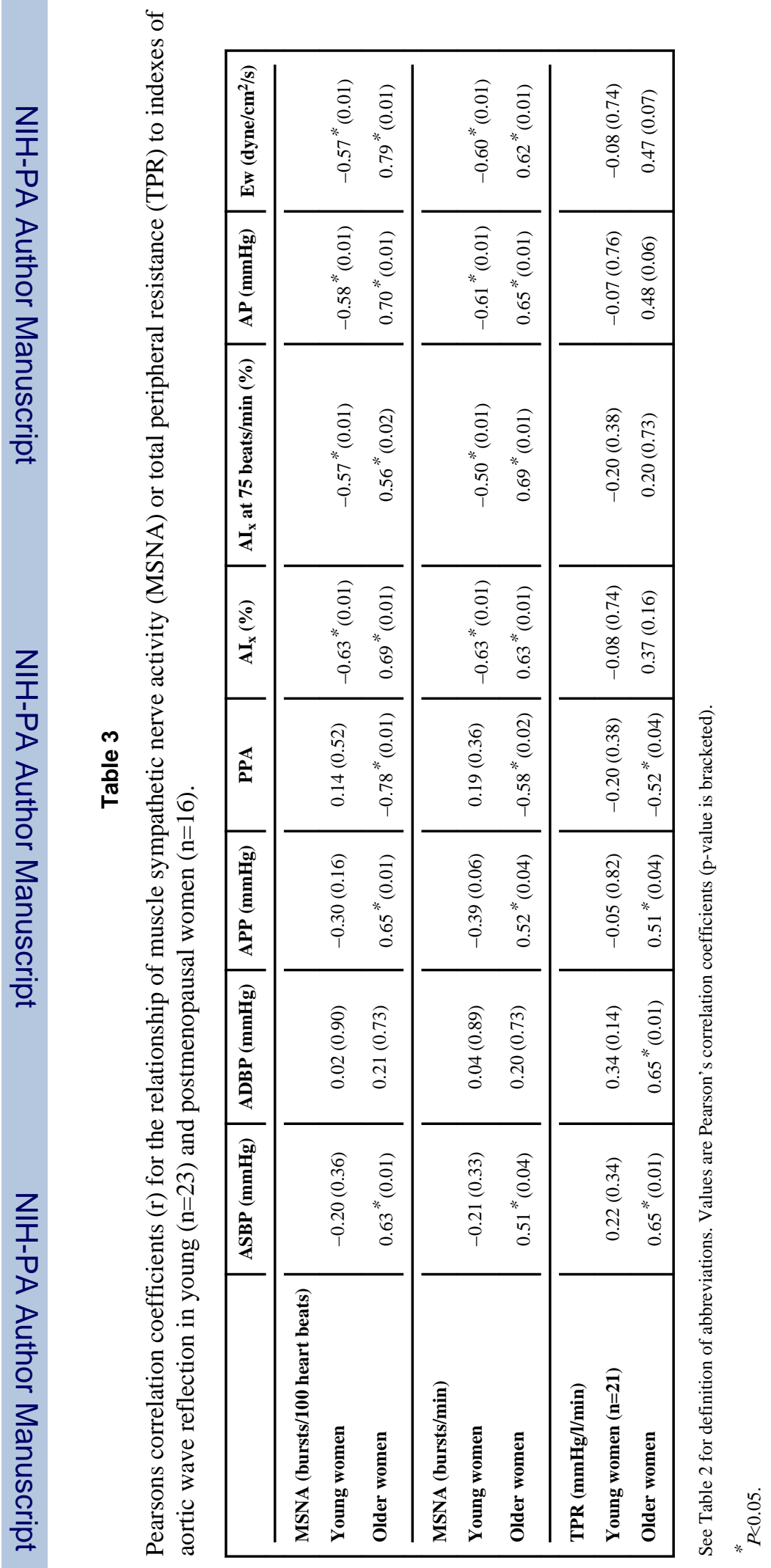

Menopause. Author manuscript; available in PMC 2014 September 01. 